\title{
Rebeldes com causa: jovens trabalhadores e a luta por direitos em tempos de repressão
}

\author{
José Pacheco dos Santos Júnior*
}

Resumo: Desde o ano de 1964, um ano após a instalação da Junta de Conciliação e Julgamento de Vitória da Conquista, Bahia, tornou-se comum a presença de crianças e jovens trabalhadores que após a demissão, desafiando seus ex-patrões por meio de ações na Justiça do Trabalho, exigiam o cumprimento da legislação trabalhista que regulamentava o trabalho do menor. Neste sentido, a partir do perfil do menor trabalhador na documentação, dos relatos constantes dos processos, das reclamações, das defesas dos empregadores e das decisões proferidas pelos magistrados, normalmente assentados sobre a legislação e a jurisprudência coeva, o artigo tem por objetivo discutir as políticas encetadas pelo regime militar no tocante ao trabalho do menor, ao tempo em que dialoga com as ações ajuizadas pelos pequenos trabalhadores entre 1964 e 1972.

Palavras-chave: trabalho do menor; Justiça do Trabalho; Sudoeste da Bahia.

\begin{abstract}
After the 1964 military coup and one year after the creation of the local labor court in Vitória da Conquista (Junta de Conciliação e Julgamento), located in Southwestern Bahia state, the labor grievances representing the demands of dismissed children and young workers under age of 18 years old increased significantly. Most of these grievances claimed the enforcement of the Brazilian labor law regarding the regulation of under-age workers. Based on these juridical sources this article analyses these grievances and discuss the changes in the labor policies regarding the child labor and under-age workers during the early years of the dictatorship (1964-1972).
\end{abstract}

Keywords: child labor; Labor Court; Southwestern Bahia.

\footnotetext{
A história política do Brasil repressivo do pós-64 é também a história sobre a repressão às crianças, aos menores (Edson Passetti).
}

* Mestrando em História Econômica na Universidade de São Paulo (USP). Bolsista CAPES. E-mail: josepsjunior@usp.br

1 PASSETTI, Edson. O menor no Brasil republicano. In: PRIORE, Mary Del (Org.). História da criança no Brasil. São Paulo: Contexto, 1991, p.147. 
Em 9 de outubro de 1967, Uady Bulos, advogado, representante de Roberto Ramos, " "brasileiro, solteiro, menor", 3 procurou a secretaria da Justiça do Trabalho de Vitória da Conquista (BA) e registrou reclamação trabalhista contra a Rádio Regional, até então o local de trabalho de seu cliente. Bulos alegou que o jovem foi injustamente suspenso dos serviços por cinco dias, sob a alegação, por parte da reclamada (a empregadora), de que havia comparecido à empresa em estado de embriaguez num dia de domingo. ${ }^{4} \mathrm{~A}$ inobservância do patrão em cumprir a Consolidação das Leis do Trabalho (CLT), que garantia o pagamento do saláriomínimo regional ${ }^{5}$ aos trabalhadores, também foi registrada nos autos iniciais da ação pelo advogado do jovem trabalhador. O desenlace do litígio, apenas onze dias após seu início, concretizou-se com um acordo entre as partes. Apesar da alçada da petição inicial ter sido definida em $\mathrm{NCr} \$ 400,00$ (quatrocentos cruzeiros novos), Roberto aceitou receber $\mathrm{NCr} \$ 280,00$ (duzentos e oitenta cruzeiros novos) parcelados em cinco prestações. Além disso, o jovem concordou em retornar ao serviço com a garantia de perceber o salário-mínimo regional - um dos pedidos de seu advogado -, ainda que em prestações semanais.

Registros de histórias singulares de crianças e jovens no mundo do trabalho e nos tribunais, como a história que abre este texto, elucidam a ousadia e a coragem desses menores trabalhadores em documentar os conflitos vivenciados em seus locais de trabalho e os dilemas que provavelmente conheceram no primeiro emprego. Essas ações comprovam a preciosidade da documentação da Justiça do Trabalho para a pesquisa histórica, conforme será abordado no presente artigo. Para fins de exemplificação empírica, apresentar-se-á os resultados parciais da pesquisa sobre os dissídios impetrados por jovens trabalhadores que, no período compreendido entre 1964 e 1972, apresentaram à Junta de Conciliação e Julgamento de Vitória da Conquista, Sudoeste da Bahia, reclamações contra os seus patrões.

Subordinada ao Tribunal Regional do Trabalho da $5^{\text {a }}$ Região, a Junta de Conciliação e Julgamento (JCJ) de Vitória da Conquista foi criada em 1962 por força da lei $n^{\circ} 4.124 / 62$. Tendo sua instalação física concretizada em 1963, teve como o seu primeiro juiz presidente o jovem bacharel Franklin Ferraz Neto. ${ }^{6}$ Contudo, este magistrado, que ocupava desde 1961 os cargos de vice-presidente e secretário jurídico da diretoria regional da Frente de Libertação Nacional, foi preso por tropas federais, em 6 de maio de 1964, sob a acusação de ser comunista e integrar o Grupo dos Onze, organizado por Leonel Brizola. ${ }^{7}$

A prisão do juiz trabalhista, assim como a do prefeito da cidade, confirmam o desconforto de vários setores conservadores da sociedade em relação à atuação e às iniciativas de apoio do governo local às propostas reformistas do presidente

2 Apesar do caráter público do processo trabalhista, este texto utiliza nomes fictícios, com o intuito de preservar as identidades dos menores trabalhadores.

3 LHIST/Uesb. Seção Processos Trabalhistas. Processo n 391/67.

4 Ibidem.

5 O salário-mínimo regional (mensal) do trabalhador adulto para esta região da Bahia (2a sub-região) era de $\mathrm{NCr}$ 63,75 (sessenta e três cruzeiros novos e setenta e cinco centavos). O mesmo salário para a capital Salvador era de $\mathrm{NCr} \$ 82,50$ (oitenta e dois cruzeiros novos e cinquenta centavos). A partir de abril de 1967, com a promulgação da lei $n^{\circ} 5.274$, o cálculo do salário-mínimo para menores não aprendizes foi escalonado na base de 50\% para os menores entre 14 e 16 anos de idade e em 75\% para os menores entre 16 e 18 anos de idade. Fonte: Anuário Estatístico do Brasil (1967) - IBGE.

6 Inicialmente, a JCJ de Vitória da Conquista tinha sob a sua jurisdição, além do município sede, os municípios de Itambé e Itapetinga. Em 1972, com a lei n 5.840, a Junta também passou a abarcar os municípios de Anagé, Barra do Choça, Belo Campo, Caatiba, Planalto, Poções e Cândido Sales.

7 Cf. VIANA, Anibal Lopes. Revista Histórica de Conquista. Vitória da Conquista: [s.n.], p. 167, 1982. 
João Goulart, a exemplo da ampliação do número de tribunais trabalhistas no interior do país. Neste sentido, José Dias aponta que, segundo o prefeito Pedral Sampaio, "essa medida [a instalação da Justiça do Trabalho em Vitória da Conquista em 1963] trouxe preocupação aos proprietários rurais e grandes comerciantes locais". 8

Com a prisão do juiz trabalhista, todas as audiências da JCJ de Vitória da Conquista foram adiadas. No processo $n^{\circ}$ 90/64 aparecia a seguinte justificativa para o adiamento: "em razão de não ter comparecido o Sr. Suplente de Juiz Presidente, Dr. Franklin Ferraz Neto, por ter sido detido, nesta Cidade, por tropas federais". 9 O bacharel Jaime Correia assumiu a presidência da Junta como juiz em junho de 1964. O novo magistrado do trabalho, segundo o jornal O Sertanejo, de Vitória da Conquista, mostrava-se um "democrata sincero, perfeitamente integrado nos postulados da Revolução que derrubou o pelego-comunismo no Brasil”.

O jornal, que defendia a posição dos militares e dos civis que apoiavam o golpe instaurado no país e, notadamente, dos conservadores da União Democrática Nacional (UDN) na cidade, fizera-se crítico ferrenho da atuação de Franklin Ferraz e comemorou a nomeação de Jaime Correia: "Vitória da Conquista, agora, vai conhecer Justiça do Trabalho, tendo à frente desse importante sactor [sic] um magistrado digno". Para os editores de O Sertanejo, Franklin Ferraz era um dos propulsores do comunismo e do contragolpe e o seu "silenciamento" traria de volta a paz e a justiça à cidade: "Não mais haverá pregações subversivas. Não se verão conselhos de invasão de terras. Os patrões, num Tribunal, realmente justo e equânime, terão vez, quando defenderem causas justas". ${ }^{10}$

A intervenção na Junta de Conciliação e Julgamento de Vitória da Conquista foi apenas um exemplo do que ocorreu no Brasil a partir do Golpe Militar de 1964. Como salienta Larissa Corrêa, "as nomeações dos magistrados dos tribunais trabalhistas e a atuação dos sindicatos foram objeto de rigoroso controle"." Segundo esta historiadora, que investigou a atuação de trabalhadores, advogados e sindicalistas em São Paulo, "logo após a instalação da ditadura militar, em março de 1964, o escritório montado por um grupo de advogados sindicalistas foi invadido pelos agentes do Deops. Alguns deles conseguiram fugir, outros foram chamados para depor". ${ }^{12}$ Já Claudiane Silva, que estudou a atuação do TRT do Rio de Janeiro no período da ditadura, ressalta: "é sabido que pelo menos um magistrado foi processado pelo próprio Tribunal Regional do Trabalho do Rio de Janeiro por ato subversivo na fundamentação de suas sentenças". ${ }^{13}$

Franklin Ferraz ficou preso por volta de 60 dias em Salvador. Posto em liberdade, retornou a Vitória da Conquista para exercer a profissão de advogado, como informa Viana. ${ }^{14}$ No entanto, o Tribunal Regional do Trabalho da $5^{\text {a }}$ Região, com sede em Salvador, em 7 de janeiro de 1965, ainda solicitava, por meio de telegrama, ao juiz presidente da JCJ de Vitória da Conquista “informações sobre o

8 DIAS, José Alves. O golpe de 1964 e as dimensões da repressão em Vitória da Conquista. In: ZACHARIADHES, Grimaldo Carneiro (org.). Ditadura militar na Bahia: novos olhares, novos objetos, novos horizontes. Salvador: EDUFBA, 2009, p. 78.

9 LHIST/Uesb. Seção: Processos Trabalhistas. Processo nº 90/64.

10 Jornal O Sertanejo, ano II, n 82, Vitória da Conquista, 6 de junho de 1964.

11 CORRÊA, Larissa Rosa. Trabalhadores têxteis e metalúrgicos a caminho da Justiça do Trabalho: leis e direitos na cidade de São Paulo - 1953 a 1964. 2007. Dissertação (Mestrado em História). Universidade Estadual de Campinas, Campinas, 2007, p. 42.

12 Ibid. p. 43 .

13 SILVA, Claudiane Torres da. Justiça do Trabalho e ditadura civil-militar no Brasil (1964-1985): atuação e memória. 2010. Dissertação (Mestrado em História). Universidade Federal Fluminense, Niterói, 2010, p. 84.

14 Viana. Op. cit., p. 345. 
paradeiro do Dr. Franklin F. Neto". ${ }^{15}$ Extremamente jovem, Franklin, “o advogado que apresentou e conseguiu, em conjunto com o prefeito, a instalação da Justiça do Trabalho e foi nomeado seu primeiro juiz", ${ }^{16}$ faleceu em 1968, antes de seu julgamento na Justiça Militar. ${ }^{17}$

Apesar da interferência de ordem política supracitada, desde a sua fundação a JCJ passou a figurar como uma importante instituição dedicada à mediação dos conflitos entre menores trabalhadores e empregadores. Dos 3.885 processos judiciais impetrados na $\mathrm{JCJ}^{18}$ de Vitória da Conquista no período que marca a primeira fase da jurisdição deste tribunal, de 1964 a 1972, 117 ações (3,01\%) têm por origem menores trabalhadores que, sob o acompanhamento de seus responsáveis legais, acionaram o judiciário trabalhista contra os seus patrões, como pode ser visualizado na Tabela 1.

Tabela 1 - Movimentação processul na JCJ de Vitória da Conquista (1963-1972)

\begin{tabular}{c|c|c} 
ANO & TOTAL DE PROCESSOS & $\begin{array}{c}\text { PROCESSOS DE MENORES } \\
\text { TRABALHADORES }\end{array}$ \\
\hline 1963 & 18 & 12 \\
\hline 1964 & 278 & 10 \\
\hline 1965 & 409 & 16 \\
\hline 1966 & 500 & 23 \\
\hline 1967 & 504 & 09 \\
\hline 1968 & 500 & 08 \\
\hline 1969 & 627 & 12 \\
\hline 1970 & 397 & 15 \\
\hline 1971 & 323 & 12 \\
\hline 1972 & 347 & \\
\hline
\end{tabular}

Fonte: Acervo do Laboratório de História Social do Trabalho - LHIST/UESB

Sobre a hipertrofia da quantidade de ações ajuizadas, Arnaldo Süssekind destaca a proeminência dos vários planos econômicos que, à época, "feriram direitos adquiridos, motivando milhares de ações trabalhistas". ${ }^{19}$ Contudo, como sugere Silva, a oscilação da movimentação processual durante o regime militar, em particular, apresentou um aumento considerável que ainda não foi profundamente analisado e que não há consenso sobre os motivos. ${ }^{20} \mathrm{Um}$ ligeiro refluxo no volume das ações nos anos iniciais da década de 1970, em âmbito regional e nacional, ainda necessita de investigações mais pormenorizadas, no sentido de sondar as motivações e tecer diálogos com outras fontes que possam acenar para a queda do movimento de processos trabalhistas, e mais ousadamente, discutir comparativamente o acesso dos trabalhadores ao judiciário trabalhista nos "anos de chumbo". Por outro lado, o ritmo ascendente da movimentação processual na primeira instância da Justiça do Trabalho em Vitória da Conquista pode ser associado, também, à demanda crescente dos trabalhadores pelo judiciário

15 LHIST/UESB. Seção Códices. Livro de registro de protocolo, 1965, p. 38.

16 DIAS. Op. cit., p.79.

17 Cf. SANTOS, Lorena Farias. Franklin Ferraz Neto e o Golpe de 1964: repercussões da ditadura militar na magistratura trabalhista de Vitória da Conquista. Anais Eletrônicos - VI Encontro Estadual de Historia da ANPUH-BA, 2013.

18 Primeira instância da Justiça do Trabalho.

19 SÜSSEKIND, Arnaldo. História e perspectivas da Justiça do Trabalho. Revista LTr, vol. 66, n² 2, p. 135-140, 2002.

20 SILVA. Justiça do Trabalho e ditadura civil-militar no Brasil, p. 52. 
trabalhista em âmbito nacional, corroborando a tese da credibilidade desta justiça especial como um espaço legítimo de negociações, como sugere os índices do Gráfico 1.

\section{Gráfico 1 - Movimentação processual nas Juntas de Conciliação e Julgamento do Brasil (1964-1972)}

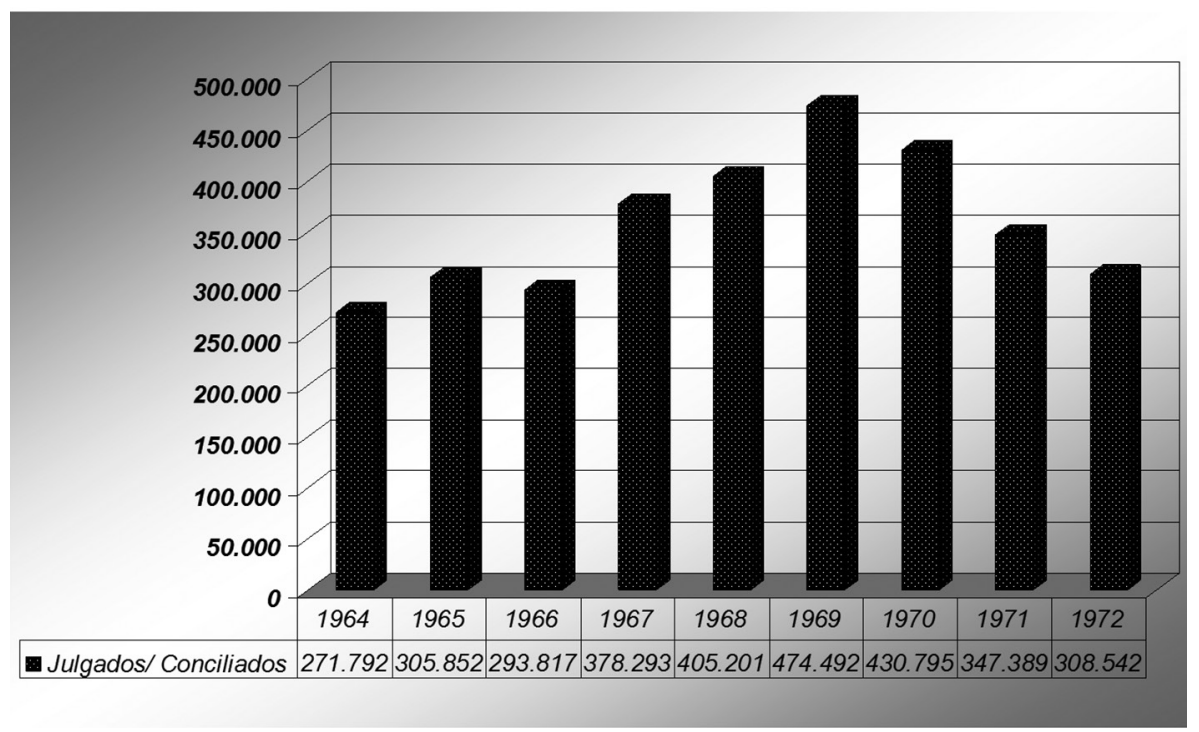

Fonte: Tribunal Superior do Trabalho

Todos os dissídios ajuizados por menores trabalhadores nesse período foram de natureza individual. Conforme apregoa o Direito Processual do Trabalho, a distinção entre dissídio individual e dissídio coletivo não se baseia na quantidade de trabalhadores na ação ajuizada, mas na natureza do objeto. Para Arion Romita, "no dissídio individual, está em jogo o direito subjetivo violado, de um ou de vários trabalhadores, todos considerados individualmente e perfeitamente identificados". ${ }^{21}$ No mesmo sentido, Wilson Batalha destaca que "os interesses envolvidos nos dissídios individuais são interesses concretos de um ou alguns, ao passo que os interesses envolvidos em dissídios coletivos são interesses genéricos, abstratos, da categoria ou grupo".22

Especificamente, a grande maioria dos reclamantes encontra-se alocada em processos com um reclamante $(88,7 \%)$ e apenas $11,3 \%$ das reclamatórias possuem mais de um reclamante, estas envolvendo irmãos, pais e filhos, ou até mesmo vários trabalhadores que reclamaram contra o mesmo empregador. Já as informações pessoais relativas aos trabalhadores são extremamente sucintas nos autos dos processos, da mesma forma como são apresentadas as reclamações ajuizadas por trabalhadores da zona canavieira de Pernambuco entre 1963 e 1965, analisadas por Christine Dabat. ${ }^{23}$

Nos dissídios dos jovens trabalhadores que acionaram a JCJ de Vitória da Conquista, as peças apresentam: nome completo, idade, ${ }^{24}$ nome e grau

21 ROMITA, Arion Sayão. Justiça do Trabalho: produto do Estado Novo. In: PANDOLFI, Dulce (org.). Repensando o Estado Novo. Rio de Janeiro: Editora FGV, 1999, p. 109.

22 BATALHA, Wilson de Souza Campos. Tratado elementar de Direito Processual do Trabalho. Rio de Janeiro: José Konfino, 1960, p. 115 (vol.I).

23 Dabat, Christine R. Uma 'caminhada penosa': a extensão do Direito trabalhista à zona canavieira de Pernambuco. Clio - Série Revista de Pesquisa Histórica, n² 26-2, p. 291-320, 2008.

24 Sobretudo a partir de 1972 o termo "menor" passa a predominar no campo destinado à idade do trabalhador. 
de parentesco do responsável legal que o acompanha na ação e o ofício desempenhado, além da data de admissão no emprego, ${ }^{25}$ salários recebidos e, por fim, a reclamação. As peças processuais mais ricas em detalhes "do cotidiano no mundo do trabalho, dos registros dos conflitos, das negociações e das interpretações do texto jurídico - são as atas das audiências dos dissídios que, a princípio, não atenderam a primeira proposta de acordo feita pelo juiz presidente. Dotadas de imenso valor para a pesquisa histórica, são também as peças comprobatórias das ações, como folhas de pagamento, certidões de nascimento, recortes de jornais, bilhetes e fotografias.

Os dados do Fundo das Nações Unidas para a Infância (UNICEF), referentes aos princípios da década de 1960, apontaram que nos países em desenvolvimento "aproximadamente $80 \%$ dos jovens do sexo masculino compõem a força de trabalho" e que "muitas moças dessa idade também estão trabalhando ou procurando trabalho, embora a proporção seja muito menor". ${ }^{26}$ Nos processos dos menores trabalhadores na JCJ de Vitória da Conquista, quando coletadas as informações acerca do sexo dos reclamantes, percebe-se a sintonia entre estes dados e as estatísticas mais gerais do período, marcadas pela proeminência da presença dos meninos no mercado formal de trabalho. Eles se encontram presentes em $68 \%$ da documentação, enquanto as meninas estão presentes em $32 \%$ dos processos.

Entretanto, um número menor de meninas trabalhadoras que o de meninos nos processos não significa que elas estivessem ausentes no mundo do trabalho. ${ }^{27}$ Muitas vezes, essas pequenas trabalhadoras estão atuando em ambientes domésticos, sem registro formal de trabalho. Diante desse fator, podemos levantar a hipótese de que estas menores encontravam-se subordinadas a condições de exploração econômica e social que se reproduziam, muitas vezes, camufladas como relações de pseudoparentesco, que delas faziam "afilhadas" ou "filhas de criação"ao invés de empregadas. Ainda no século XX, reafirmavam-se, nas relações de trabalho que envolviam crianças e adolescentes do sexo feminino, valores e papéis de gênero arraigados na sociedade, que naturalizavam a inferioridade feminina e reservavam prioritariamente às meninas o serviço doméstico.

Para iniciar um processo, o trabalhador deveria apresentar sua reclamação à secretaria da Junta de Conciliação e Julgamento com a jurisdição que contemplasse sua região. Já os trabalhadores de municípios que não estavam sob a alçada de alguma JCJ poderiam iniciar seu processo na Justiça comum. Após a apresentação da reclamação, ${ }^{28}$ fosse através da petição escrita, geralmente com o auxílio de um advogado, ou através do termo de reclamação verbal, o juiz presidente autuava a queixa e notificava o reclamado (aquele cuja ação judicial lhe é impetrada) a comparecer à audiência marcada para conciliação. A audiência iniciava-se com a defesa do reclamado, na sequência, o juiz presidente realizava a primeira proposta de acordo. Caso a conciliação fosse rejeitada pelas partes envolvidas no processo, o trabalhador, em seguida, era interrogado pelo juiz presidente que, logo após, promovia uma nova proposta de acordo. Não havendo conciliação, a JCJ definia

25 Em alguns autos iniciais é possível perceber o registro da data de demissão.

26 UNICEF. A infância dos países em desenvolvimento. Tradução de Donaldson M. Garschagen. Rio de Janeiro: Edições GRD, 1964, p. 119.

27 Cf. MOURA, Esmeralda Blanco Bolsonaro de. Meninas no mundo do trabalho: uma discussão necessária. In: SAMARA, Eni de Mesquita (org.). Trabalho feminino e cidadania. São Paulo: Humanitas, 2000; RIZZINI, Irma. Pequenos trabalhadores do Brasil. In: PRIORE, Mary Del (org.). História das crianças no Brasil. $2^{a}$ ed. São Paulo: Contexto, 2000.

28 Art. 840 da CLT. 
uma nova sessão da audiência para ouvir as testemunhas de ambas as partes e finalmente emitir uma sentença.

Em 27 de maio de 1966, a JCJ de Vitória da Conquista foi palco de mais uma das corriqueiras audiências destinadas a promover a conciliação entre trabalhadores e patrões. Nessa data, o processo de uma jovem de 17 anos de idade, que trabalhava como servente no Hospital Regional de Vitória da Conquista e que alegou demissão sem justa causa, foi objeto de contestação. O provedor do hospital, Renato Vaz Rebouças, em sua defesa inicial, argumentou que não houve a demissão da reclamante e que a mesma foi suspensa por duas vezes, tendo sido a primeira por sete dias e a segunda por quinze. Além disso, o provedor alegou que nos últimos tempos a jovem "tornou-se uma empregada indisciplinada, dando causa, por isso mesmo, às duas suspensões feitas" e que "ao fim da segunda suspensão a servente não retornou ao serviço, caracterizando abandono de emprego". ${ }^{29}$

Desse modo, o representante da instituição hospitalar desqualificou a reclamação ajuizada pela jovem trabalhadora e os pagamentos/ indenizações por ela solicitados, ao registrar que "assim sendo, não faz jus à indenização de antiguidade, aviso prévio, $13^{\circ}$ salário a partir da vigência desta lei, férias em dobro e simples, diferenças de salários, horas extras, remuneração dos domingos e feriados". ${ }^{30}$ Solicitou ainda que a reclamação fosse julgada improcedente e que a reclamante fosse condenada nas custas e demais cominações da lei.

Para além das questões que pertencem à esfera das negociações e táticas de acusação e defesa, a crítica situação financeira da Santa Casa de Misericórdia de Vitória da Conquista, que havia assumido a responsabilidade administrativa do Hospital, deve ter pesado no momento da definição do acordo:

Durante o mandato do provedor Renato Vaz Rebouças, a situação financeira do hospital permanecia difícil com dívidas com fornecedores. O Hospital Crescêncio Silveira, que se encontrava sob a coordenação da Santa Casa, estava dando um grande prejuízo [... $]^{31}$

Na maioria dos processos, os menores trabalhadores haviam sido demitidos e muitos são os motivos das demissões que eles próprios e seus patrões alegam em seus discursos. Um menor trabalhador podia ser demitido após pedir aumento de salário. ${ }^{32}$ Mas os mecanismos mais comuns utilizados pelos empregadores para excluí-los do serviço eram alegações de indisciplina, como no caso da jovem servente de Hospital e de um jovem que recorreu à Justiça do Trabalho de Vitória da Conquista por duas vezes no ano de 1969.

Aos 13 de março de 1969, João Lima, brasileiro, solteiro, com 17 anos de idade, devidamente assistido por sua genitora, dona Tereza Lima, iniciava sua segunda reclamação trabalhista contra a COSIC (indústria e comércio de sisal). Sua primeira reclamação, datada de 11 de fevereiro de 1969, foi arquivada, resultado do não comparecimento do jovem à audiência marcada para conciliação. No segundo processo, o menor manteve a maioria dos direitos reclamados quando ajuizou a primeira ação, excetuando-se os pedidos de diferença salarial, horas extras e

29 LHIST/UESB. Seção Processos Trabalhistas. Processo n 192/66.

30 Ibidem.

31 ROCHA, Francisco Paulo Ribeiro. A Santa Casa: História da Santa Casa de Vitória da Conquista (1914 a 2008). Vitória da Conquista: Brasil Artes Gráficas Ltda., 2009, p.57.

32 LHIST/UESB. Seção Processos Trabalhistas. Processo n 457/66. 
remuneração dos feriados civis e religiosos. Além de acrescentar o pedido do pagamento dos salários retidos e enfatizar que sua jornada de trabalho era de 10 horas e 30 minutos, quando não faltava sisal na empresa "ou quando as máquinas não sofressem avaria". ${ }^{33} \mathrm{Em} 26$ de março, na audiência marcada, o patrão em sua defesa inicial argumentou que o reclamante não foi despedido e destacou que

duas reclamações foram apresentadas perante esta MM. Junta contra a reclamada: na primeira, não pode haver apreciação do seu conteúdo, porque, faltoso como era o reclamante no serviço, quiz (sic) faltar também perante a Justiça do Trabalho, a quem injustificadamente recorreu. ${ }^{34}$

A defesa prossegue pondo em questão a idoneidade e a assiduidade do jovem ao trabalho, como também nos próprios compromissos gerados pelos trâmites da ação movida no Judiciário: "mesmo havendo a reclamada pedido à Junta uma tolerância de 15 minutos, o reclamante não compareceu. Provavelmente estava jogando snooker nos bares próximos ao estabelecimento da reclamada, onde várias vezes já foi chamado para o trabalho". ${ }^{35}$ Mais adiante, o advogado questiona os direitos solicitados pelo menor", além de enfatizar que após o reclamante faltar por cerca de 15 dias seguidos, a empresa não mais o aceitou no serviço, surgindo, então, a sua representante legal, dona Tereza, a pedir "insistentemente" a volta do rapaz, no que foi atendido, com a condição de se responsabilizar pelas faltas e atos de indisciplina.

As bases cujos discursos estão ancorados nestes dois processos expressam uma das principais estratégias de defesa utilizadas pelo patronato: a desqualificação dos comportamentos dos menores trabalhadores - a transgressão do poder disciplinar - como forma direta de descaracterizar as ações por eles impetradas, além da negação das demissões e, em alguns casos, a negação dos próprios vínculos empregatícios. A defesa do patrão, no processo de João, depois de corroborar que o jovem é um "viciado no jogo de snooker" e "que vive nos bares", ${ }^{36}$ finaliza seu discurso salientando a impropriedade de um possível acordo com um empregado que não faz jus à causa, como forma, também, de não estimulálo a persistir em tal conduta e de não se tornar uma má referência aos colegas de trabalho: "por isso não poderia a reclamada indenizar e nem fazer acordo com um empregado assim, sob pena de estimulá-lo a percorrer os mesmos caminhos em outro emprego, e, ainda, dar um mau exemplo aos outros empregados". ${ }^{37}$ Como os autos evidenciam tão claramente, nos discursos dos patrões e, até mesmo na argumentação dos responsáveis dos menores trabalhadores, o trabalho ganhava vigorosos contornos pedagógico-moralizadores.

A distância entre lei e prática notabilizada na documentação, a inobservância da legislação e a ineficiência (ou ausência) de instituições que objetivassem fiscalizar o trabalho do menor desdobravam-se na contrariedade dos discursos de caráter protetor que ganhavam terreno em canais de circulação internacional, como nos relatórios do UNICEF e nas declarações da Organização Internacional do Trabalho (OIT).

33 LHIST/UESB. Seção Processos Trabalhistas. Processo n 138/69. 
No alvorecer da década de 1960, as necessidades da própria juventude, em relação ao trabalho e à preparação para este, foram sumarizadas pelo diretor geral da OIT. O treinamento apropriado antes do ingresso no mundo do trabalho, a importância da aprendizagem, a proteção sanitária especial e a recomendação de repouso estavam presentes nos itens elencados..$^{38}$ Ainda que a execução de tais recomendações parecesse utópica em realidades onde o labor infantojuvenil era uma fonte complementar (e muitas vezes fundamental) ao orçamento doméstico, os jovens, em grande parte, não tinham muitas possibilidades concretas de optar por melhores condições de trabalho. Isso parece confirmar a descrição feita pelo diretor geral da OIT, em 1960, sobre as condições que aguardam a criança ou o adolescente que adentra no mercado de trabalho pela primeira vez:

Apesar de todo o progresso feito nos últimos anos - que não foi pequeno - o jovem de meados do século XX tem uma possibilidade pouco maior que 50\% de obter qualquer educação. Se estiver incluído na metade afortunada, terá frequentado a escola até os 12 ou 14 anos... Poderá não encontrar emprego ao deixar a escola - suas possibilidades são especialmente diminutas num país que sofra de qualquer grau apreciável de desemprego - e tem 2 vezes mais possibilidade de perder seu emprego que um adulto. Se tiver bastante sorte para conseguir um emprego, é provável que se adapte a ele; em muitos casos, aceitará o primeiro que lhe for oferecido. 39

Mesmo levando-se em consideração que as causas da existência do trabalho de crianças e adolescentes são múltiplas, sendo, por isso, mais cauteloso evitar deduções de causa e efeito para explicar as especificidades deste tipo de mão de obra, a evidência da perpetuação do círculo vicioso da pobreza revela-se como uma possível e inexorável resultante do mosaico de fatores que permeiam o trabalho precoce. ${ }^{40}$ Corolário de um universo de limitações, da incômoda incidência da evasão escolar, de poucas escolhas e da conjugação de heranças culturais e econômicas legitimadoras do trabalho de crianças e adolescentes, o ingresso precoce no mercado de trabalho, como salienta Esmeralda Moura, "não é, portanto, somente decorrência da exclusão social, mas um sólido caminho em direção à sua perpetuidade". ${ }^{41}$

Depositário fiel dos elementos mais essenciais à edificação de uma moralidade pré-estabelecida, o trabalho se apresentou, ao longo da história do Brasil e, notoriamente no discurso das elites econômicas, sociais e políticas, como um "caminho enobrecedor" direcionado às crianças e adolescentes das classes menos abastadas. Ao mesmo tempo em que se apresentava como um meio para angariar alguma renda, um complemento ao parco orçamento doméstico, no pensamento predominante o labor também se mostrava como um contraponto às supostas traquinagens e prováveis vícios ofertados pelas ruas.

Esmiuçando o perfil do menor trabalhador na documentação da JCJ de Vitória da Conquista, visualiza-se a presença majoritária de jovens trabalhadores

38 Apud UNICEF. A infância dos países em desenvolvimento, p. 122.

39 Report of the Director-General [Report I], International Labour Conference, 44th Session "Youth and Work" (Part I) International Labour Organisation, Genebra, 1960 [UNICEF. A infância dos países em desenvolvimento, p. 119-120].

40 Um alerta feito por ELÍAS, Cristina Amich. El trabajo de los menores de edad en la dictadura franquista. Historia Contemporánea, $\mathrm{n}^{\circ}$ 36, p. 169-192, 2008.

41 MOURA. Meninas no mundo do trabalho, p. 82. 
a partir dos 16 anos de idade. Eles ajuizaram 44,3\% das ações trabalhistas movidas por menores trabalhadores entre 1964 e 1972. Os números que evidenciam o lugar de destaque dos adolescentes no mercado formal de trabalho da região sudoeste da Bahia estão em sintonia com dados sobre o trabalho infantojuvenil em cenários mais amplos. Para as décadas de 1950 a 1980, os censos demográficos do IBGE destacam o maior número de adolescentes no mercado formal de trabalho, como também indicam uma redução do número de crianças e jovens no mercado de trabalho durante a década de 1970, mas com tendência ao crescimento a partir da década seguinte, como pode ser visualizado no Gráfico 2.

\section{Gráfico 2 - Porcentagem de crianças (10-14 anos) e jovens (15-19 anos) trabalhadores no total dos respectivos grupos etários, Brasil, 1950-1980}

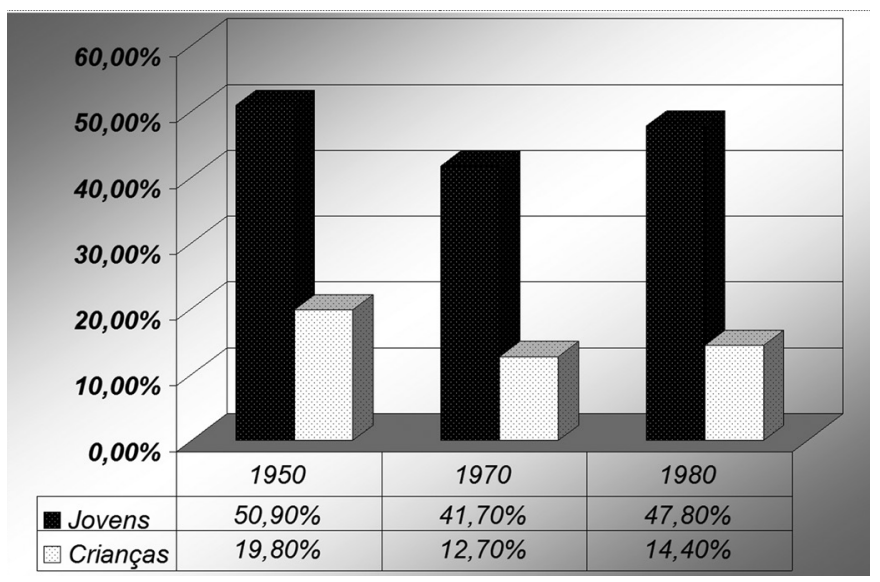

Fonte: Dados dos Censos Demográficos do IBGE ${ }^{42}$

Nesta perspectiva, aos estudos que têm como foco a discussão sobre o trabalho precoce, um adendo especial sobre as distintas motivações que incidem na entrada de crianças e adolescentes no mundo do trabalho se reveste de salutar importância. Como notou Irma Rizzini, "os trabalhadores infantis, na maioria dos casos, são vítimas da miséria". ${ }^{43}$ Sobre os adolescentes, há outros motivos, além da pobreza, que os levam ao trabalho:

Nesta faixa de idade, os fatores individuais, como querer ter seu próprio dinheiro, ser mais livre, ter ocupação ou qualificação se somam aos culturais, como a crença de que filho de pobre tem que trabalhar ou que o trabalho é disciplinador, e aos fatores socioeconômicos, como a necessidade de ajudar no orçamento familiar. É comum o próprio adolescente tomar a iniciativa de trabalhar, no que é incentivado pela família. ${ }^{44}$

Da mesma forma, como concluiu Michelle Perrot ao estudar os jovens operários franceses nos Oitocentos, "a relação com o trabalho é sem dúvida alguma o que mais distinguiu a infância, da juventude operária, no século XIX”. ${ }^{45}$

42 OIT - ORGANIZAÇÃO INTERNACIONAL DO TRABALHO. Combatendo o trabalho infantil: guia para educadores/IPEC. Brasília: OIT, 2001, v.2, p. 53.

43 RIZZINI, Irma. Pequenos trabalhadores do Brasil, p.386.

44 Ibidem, p. 387-388.

45 PERROT, Michelle. La juventud obrera. Del taller a la fábrica. In: LEVI, Giovanni; SCHMITT, Jean-Claude (orgs.). Historia de los jóvenes II: la edad contemporánea. Trad. de María Barberán. Madrid: Taurus, 1996, p. 125. 
Para Perrot, gradativamente as crianças foram se tornando alvo de disputa entre a escola e a fábrica. Nesse sentido, a autora enfatiza que os menores de treze anos desapareceram das minas e das grandes oficinas no transcurso do século XIX. No entanto, semelhante horizonte não se anunciou aos adolescentes: "passados os treze anos, e com as citadas restrições, o trabalho foi a regra". ${ }^{46}$

Em 1963 veio a público o relatório "Children of the Developing Countries" do UNICEF. Traduzido e publicado no Brasil em 1964, o documento provocou o questionamento quanto à eficácia da delimitação da idade mínima para a admissão ao emprego nos países em desenvolvimento, a exemplo dos territórios latinoamericanos. Enfatizando a inoperância histórica deste tipo de legislação em tais regiões, o relatório apontava a ausência de mecanismos efetivos de fiscalização quanto ao labor infantojuvenil, principalmente nas zonas rurais: "o trabalho e seus problemas começam em tenra idade nos países em desenvolvimento. A idade mínima legal para admissão em empregos varia de 12 a 16 anos em diferentes países, mas nem sempre isso é cumprido; na verdade, em áreas rurais, raramente é cumprido". 47

Em relação ao Brasil, a CLT estava particularmente voltada para a regulamentação do trabalho urbano e os pequenos trabalhadores do campo tiveram de esperar a década de 1960 para vislumbrar uma legislação voltada especialmente ao trabalho rural - o Estatuto do Trabalhador Rural, de 1963 e, especialmente, os seus artigos 57 ao 61, que visavam regulamentar o trabalho rural do menor. ${ }^{48}$

No que concerne à remuneração do empregado rural menor de dezesseis anos, ficou assegurado um salário-mínimo, fixado em valor correspondente à metade do salário-mínimo estabelecido para o adulto. Quanto ao empregado rural maior de dezesseis anos, ficou assegurado um salário-mínimo igual ao do empregado adulto. No que concerne ao registro dos pequenos trabalhadores, antes da CLT, o decreto-lei $\mathrm{n}^{\circ} 3.616$ de 1941, entre outras matérias, instituiu a carteira de trabalho do menor, conforme consta em seu artigo 12: "fica instituída a Carteira de Trabalho do Menor para todos os menores de 18 anos, sem distinção de sexo, empregados em empresas, ou estabelecimentos, de fins econômicos e naqueles que Ihes forem equiparados". ${ }^{49}$ Somente em 1969, com a aprovação do decreto-lei $n^{\circ}$ 926, de 10 de outubro de 1969, a Carteira Profissional, a Carteira de Trabalho do Menor e a Carteira Profissional do Trabalhador Rural foram unificadas em um único documento: a Carteira de Trabalho e Previdência Social. ${ }^{50}$

Sob pressão dos organismos internacionais e condicionada por diversos interesses políticos, econômicos e por distintos projetos sociais, a legislação brasileira concernente ao trabalho do menor sofreu diversas transformações ao longo do século XX. Algumas características foram mantidas, a exemplo da proibição do trabalho noturno aos menores de dezoito anos.

46 Ibidem.

47 UNICEF. A infância dos países em desenvolvimento, p. 119.

48 BRASIL. Lei n 4.214, de 2 de março de 1963. Dispõe sobre o “Estatuto do Trabalhador Rural”. Disponível em < http://www010.dataprev.gov.br/sislex/paginas/42/1963/4214.htm>. Acessado em 30 de abril de 2014.

49 BRASIL. Decreto-lei $n^{\circ} 3.616$, de 13 de setembro de 1941. Dispõe sobre a proteção do trabalho do menor e dá outras providências. Disponível em: <http://legis.senado.gov.br/legislacao/ListaPublicacoes.action?id=30257>. Acessado em 30 de abril de 2014.

50 BRASIL. Decreto-lei n 926, de 10 de outubro de 1969. Institui a Carteira de Trabalho e Previdência Social, altera dispositivos da Consolidação das Leis do Trabalho e do Estatuto do Trabalhador Rural, e dá outras providências. Disponível em <http://www.planalto.gov.br/ccivil_03/decreto-lei/1965-1988/Delog26.htm>. Acessado em 30 de abril de 2014. 
No período de 1932 a 1988, a idade mínima para admissão ao emprego ou trabalho foi alterada várias vezes: entre 1932 e 1967, foi 14 anos de idade, em 1967 foi reduzida para 12 anos de idade, e em 1988 foi reposto a 14 anos de idade, onde permaneceu até 2000. Várias características da lei se mantiveram constantes ao longo deste período: os menores de dezoito anos não poderiam trabalhar durante a noite ou se envolver em qualquer tipo de emprego ou trabalho que, por sua natureza ou pelas circunstâncias em que foi realizado, comprometesse a sua saúde, segurança ou moral. ${ }^{51}$

Quanto à delimitação da idade mínima para a admissão ao emprego, é notável o retrocesso dado à matéria em 1967: a Constituição imposta pelos militares e o decreto-lei $n^{\circ} 229$ suprimiram o dispositivo constitucional que proibia a diferença salarial em função da idade do trabalhador e reduziram a idade mínima de 14 para 12 anos..$^{22} \mathrm{O}$ artigo $8^{\circ}$ do referido decreto-lei $n^{\circ} 229$, apresentou nova redação a 15 artigos do Capítulo IV do Título III da CLT (Da proteção do trabalho do menor), adequando a matéria aos preceitos econômicos da nova Constituição do país, travestidos na política de Segurança Nacional. O artigo 402, por exemplo, com seu novo texto, passou a exprimir que "considera-se menor para efeitos desta Consolidação o trabalhador de 12 a 18 anos". Já o artigo 403 passou a proibir o trabalho dos menores de 12 anos de idade, além de determinar que o trabalho dos menores de 12 a 14 anos ficaria sujeito a duas condições: garantia de frequência à escola que assegurasse a formação ao menos no nível primário; a obrigatoriedade dos serviços de natureza leve, que não fossem nocivos à saúde e ao "desenvolvimento normal" do menor. ${ }^{53}$ Além disso, este artigo veio solucionar o conflito gerado na Constituição, art. $168, \S 3^{\circ}, n^{\circ}$ II, que dispõe: "o ensino dos sete aos quatorze anos é obrigatório para todos e gratuito nos estabelecimentos primários oficiais". ${ }^{4}$

Esta política tinha por justificativa a eliminação dos "males" que poderiam se desdobrar à suposta ociosidade infantil, assim como pretendia regulamentar o período que compreendia o término da escolarização obrigatória e a idade mínima para a admissão no mercado formal de trabalho. Rotulada juridicamente como o "hiato nocivo", a criança, terminando o curso primário aos 12 anos, ficava legalmente impedida de trabalhar até os 14 anos. ${ }^{55}$ Para o economista Dorival Teixeira Vieira que, em 1967, na revista Problemas Brasileiros, questionou e combateu as alternativas adotadas para solucionar o hiato entre a escola e o

51 OLIVEIRA, Oris de. Development of Child Labor Law in Brazil. In: HINDMAN, Hugh D. (org.). The World of Child Labor: An Historical and Regional Survey. Armonk, NY: M.E. Sharpe, 2009, p. 358 (Tradução livre).

52 BRASIL. Decreto-lei ${ }^{\circ}$ 229, de 28 de fevereiro de 1967. Altera dispositivos da Consolidação das Leis do Trabalho, aprovada pelo decreto-lei $\mathrm{n}^{\circ} 5.452$, de $1^{\circ}$ de maio de 1943 , e dá outras providências. Disponível em < http://www.planalto.gov.br/ccivil_03/decreto-lei/delo229.htm>. Acessado em 30 de abril de 2014.

53 No tocante à proteção e saúde do menor trabalhador, em fevereiro de 1970, Médici publicou o decreto $n^{\circ} 66.280$, que dispunha sobre condições para o trabalho de "menores" de 12 a 14 anos, reafirmando a condição, já estabelecida em normas anteriores, de que "os trabalhos não sejam nocivos à saúde e ao desenvolvimento normal do menor". Frente à omissão da CLT na definição de "serviços de natureza leve", este decreto estabeleceu que eles constituíssem "unicamente os presentes em atividades não compreendidas nos ramos de indústria, de transportes terrestres e marítimos, nem nos que trata o artigo 405 da mesma Consolidação". RIBEIRO, Herval Pina; LACAZ, Francisco A. de Castro. O trabalho da mulher e do menor. São Paulo: Dep. Intersindical de Estudos e Pesquisas de Saúde e dos Ambientes de Trabalho, 1984, p. 146.

54 Comentários: A Constituição de 1967 e os direitos trabalhistas - Alterações da Consolidação das Leis do Trabalho (Decreto-lei. $n^{\circ} 229$, de 28 de fevereiro de 1967). Revista Legislação do Trabalho, São Paulo, Ano 31, p. 121-136, 1967, p. 123.

55 VIEIRA, Dorival Teixeira. Trabalho do menor, escolaridade e desenvolvimento econômico. Problemas Brasileiros, São Paulo, n 52, p. 13, 1967. 
trabalho do menor, esta questão derivava "única e exclusivamente do escasso período de escolaridade". Ao emitir sua opinião, Vieira endossou o acalorado debate que foi promovido em torno desse tema e exortou o peso fulcral da educação como a alternativa mais adequada para a resolução do hiato.

$\mathrm{Na}$ disposição constitucional analisada, mais que cegueira, vemos enorme imprevidência nesta precocidade do trabalho do menor que a lei procura perpetuar. Elimina-se o hiato nocivo com um dispositivo mais nocivo ainda. E isto se dá porque é muito mais fácil e sedutor aplicar verbas em outros setores da atividade, do que destiná-las à educação. ${ }^{56}$

Desta forma, os projetos governamentais destinados ao trabalho do menor no pós-1967 indicam, claramente, a tentativa de criar condições legais para a ampliação de um mercado de mão de obra excedente e pouco onerosa. Sob essa política, em abril de 1967, dois meses após a promulgação do decreto-lei $n^{\circ} 229$, a matéria do direito trabalhista referente ao menor ganhou nova regulação: a lei $n^{\circ} 5.274 / 67$, cujo teor apresentava novas disposições sobre o salário-mínimo de menores. 57

Mário Henrique Simonsen e Roberto Campos, responsáveis pela estruturação da política econômica coeva, justificaram que as diversas transformações macroeconômicas consumadas no período 1964-1967 tinham como objetivo remover cinco "falhas institucionais": "a) a ficção da moeda estável na legislação econômica; b) a desordem tributária; c) a propensão ao déficit orçamentário; d) as lacunas do sistema financeiro; e) os focos de atrito criados pela legislação trabalhista". ${ }^{58}$ Em 1966, em particular, entrava em vigor o Fundo de Garantia por Tempo de Serviço (FGTS), tornando-se uma alternativa à estabilidade decenal do trabalhador" ${ }^{59}$ e "aumentando a flexibilidade da contratação e demissão da mão de obra". ${ }^{60}$ Se por um lado, a adoção dessas medidas deu relevo à face da política econômica empreendida desde o golpe com vistas à contenção da inflação, sobretudo através do controle salarial, todas essas mudanças, como sugere Silvanir Miranda, também estão calcadas na conjuntura do período, em que eram "lançadas as bases para a expansão econômica de 1968-73 programada pelo regime militar", ${ }^{61}$ período conhecido como "milagre econômico".

A lei $n^{\circ} 5.274 / 67$, por exemplo, revogou alguns artigos do decreto-lei $n^{\circ} 229$, principalmente no tocante à regulamentação da aprendizagem. Se antes aprendizes eram aqueles que tinham entre 12 e 18 anos, sujeitos à formação metódica, percebendo salário conforme o período de aprendizagem em que se encontravam, ${ }^{62}$ com a lei $n^{\circ} 5.274$, aprendizes foram definidos como aqueles menores que estivessem entre a faixa etária de 14 a 18 anos e submetidos à

56 Ibidem, p. 15, grifo nosso.

57 BRASIL. Lei $n^{\circ}$ 5.274, de 24 de abril de 1967. Dispõe sobre o salário-mínimo de menores, e dá outras providências. A lei $n^{\circ} 5.274 / 67$ foi revogada em julho de 1974, através da lei $n^{\circ} 6.086$.

58 Apud NAPOLITANO, Marcos. 1964: História do regime militar brasileiro. São Paulo: Contexto, 2014, p. 152.

59 Cabia ao trabalhador optar ou não pela adesão ao regime do FGTS.

60 PRADO, Luiz Carlos Delorme; EARP, Fábio Sá. O “milagre” brasileiro: crescimento acelerado, integração internacional e concentração de renda (1967-1973). In: FERREIRA, Jorge; DELGADO, Lucilia de Almeida Neves (org.). O tempo da ditadura: regime militar e movimentos sociais em fins do século XX. $6^{\text {a }}$ ed. Rio de Janeiro: Civilização Brasileira, 2013, p. 215 (O Brasil Republicano; vol.4).

61 MIRANDA, Silvanir Marcelino de. Infância, trabalho e direitos no Vale do Mucuri - MG. 2006. Tese (Doutorado em História Social). Universidade de São Paulo, São Paulo, 2006, p. 172.

62 Na primeira metade da duração máxima prevista para o aprendizado seria pago salário nunca inferior a meio salário-mínimo e na segunda metade, passaria a receber, pelo menos, 2/3 do salário-mínimo regional. 
formação profissional. Além disso, o salário só poderia ser fixado em até metade do estatuído para os trabalhadores adultos da região. Contudo, a execução deste artigo não importava em diminuição de salários para os que estivessem trabalhando sob condições pecuniárias mais vantajosas. Já para os menores trabalhadores não portadores de curso completo de formação profissional, a lei $n^{\circ} 5.274,{ }^{63}$ promoveu o seguinte escalonamento no cálculo do salário: 50\% para os menores entre $14 \mathrm{e}$ 16 anos de idade e em 75\% por cento para os menores entre 16 e 18 anos de idade.

Sobre estas recorrentes e até súbitas modificações legislativas, Walküre Silva ${ }^{64}$ argumenta que no plano infraconstitucional, legislou-se interinamente, ou seja, essa atividade normativa, caracterizada pela protuberância dos decretos e decretos-leis, fruto da concentração do poder nas mãos do Executivo, alimentou as necessidades apresentadas pelo regime ditatorial, como complementa Moraes Filho e Moraes:

\begin{abstract}
Seria impossível enumerar todas as medidas de natureza trabalhista, umas boas, outras más, de vez que estávamos vivendo num regime de exceção[...]. Emface de febre legiferante da chamada institucionalização por intermédio de leis, decretos-leis e decretos, nunca se sabia quando se estava no começo, no meio ou no fim do processo legislativo. Como na época do governo discricionário getuliano, leis eram feitas hoje para serem alteradas amanhã, no todo ou em parte, ou num simples parágrafo, com colaboração ou não do Congresso Nacional, não raro em recesso decretado pelo Executivo, que passava a legislar em seu lugar (...) ${ }^{65}$
\end{abstract}

Além disso, Regina Lucia Morel e Elina Pessanha ressaltam que "o regime autoritário de 1964 estrategicamente suspendeu alguns direitos importantes, como a estabilidade, e reforçou o uso dos aspectos repressivos já contidos na legislação vigente desde 1943". ${ }^{66}$ As autoras ainda salientam que "há muitas indicações de que a Justiça do Trabalho, cuja estrutura permaneceu a mesma na Constituição de 1967 e não foi alterada pela Emenda Constitucional de 1969, representou, durante esse período autoritário, um dos poucos espaços de defesa de direitos sociais". ${ }^{67}$

\section{Considerações finais}

Na década de 1990, Claudio Batalha, em um texto sobre as fontes para a historiografia do movimento operário, já alertava para a necessidade de "empreender uma reavaliação das fontes tradicionais e de ampliar o leque das fontes empregadas". ${ }^{68}$ Batalha chamava atenção, então, para a possibilidade de releitura de fontes tradicionais (como jornais e textos literários) e, ainda, sugeria

63 BRASIL. Lei n 5.274, de 24 de abril de 1967. Dispõe sobre o salário-mínimo de menores, e dá outras providências. Disponível em: < http://www.planalto.gov.br/ccivil_03/leis/L5274.htm>. Acessado em 30 de abril de 2014.

64 SILVA, Walküre Lopes Ribeiro da. Direito do Trabalho brasileiro: principais aspectos de sua evolução histórica e as propostas de modernização. Rev. TST, Brasília, vol.69, n² 2, p. 120-138, p. 131, 2003.

65 Apud Ibidem, p. 131.

66 MOREL, Regina Lucia M; PESSANHA, Elina G. da Fonte. A justiça do trabalho. Tempo Social: revista de sociologia da USP, v.19, n², p. 87-109, p. 91, 2007.

67 Ibidem.

68 BATALHA, Claudio. A historiografia da classe operária no Brasil: trajetória e tendências. In: FREITAS, Marcos Cezar de (org.). Historiografia brasileira em perspectiva. $2^{\text {a }}$ ed. São Paulo: Contexto, 1998, p. 156. 
a utilização de "novas" fontes, a exemplo dos processos da Justiça do Trabalho. Mais recentemente, Antonio Luigi Negro, ${ }^{69}$ em um texto dedicado a avaliar a importância dos arquivos dos tribunais trabalhistas para a construção da História Social do Trabalho, argumenta favoravelmente à implantação de ações destinadas à preservação e à efetiva utilização dos processos da Justiça do Trabalho como fontes para a pesquisa histórica e denuncia a tendência à destruição e descarte em massa que essa documentação vem sofrendo ao longo dos últimos anos sob o aval da lei $n^{\circ} 7.627$, de 10 de novembro de $1987 .{ }^{70}$

Aliando o nefasto impacto desta lei às limitações de acesso às poucas fontes preservadas, só muito recentemente a historiografia passou a se ocupar de tais questões com mais intensidade, fruto do estímulo proporcionado pela criação de centros de documentação, das políticas de acesso à documentação do período da ditadura militar e do apoio de operadores do Direito empenhados na causa da preservação e pesquisa com essas fontes.

Como proposta desta investigação, a oportunidade de reflexão que se abre em torno do papel que a Justiça do Trabalho desempenhou - e desempenha - como uma instituição, representante do Estado, devotada à mediação de contendas laborais, se coloca na ordem do dia. É, portanto, nesta seara que esta pesquisa está inserida e pretende ser uma contribuição, simultaneamente, à História da Juventude, à História do Trabalho e à História do Judiciário, trazendo à baila o debate sobre os processos e a atuação de jovens trabalhadores na luta por direitos frente à Justiça. Essencialmente, visa-se romper com as barreiras que durante muito tempo dominaram a historiografia brasileira sobre o trabalho livre, atada à discussão sobre as experiências dos trabalhadores "organizados", adultos e pertencentes aos grandes centros urbanos, particularmente São Paulo e Rio de Janeiro.

Nesse sentido, a análise preliminar da documentação da Justiça do Trabalho, da pesquisa de mestrado ora em curso, indica que os menores trabalhadores e seus responsáveis legais, utilizando a lei como escudo, enfrentaram os meandros judiciais na busca pelo cumprimento de seus direitos, defenderam suas versões, seus valores, e, do mesmo modo, os patrões, advogados e juízes também expuseram suas interpretações, fazendo do Judiciário um campo de disputas.

Não apenas evidenciando a mediação de contendas acerca de pagamentos, direitos sonegados ou conflitos cotidianos entre empregados e empregadores, as páginas que compõem os autos dos processos trazem valiosos registros que revelam as diversas leituras que os atores sociais, envolvidos nas querelas, faziam do texto jurídico. Como consequência, o florescimento do debate sobre o reconhecimento dos sujeitos que "mereciam" estar sob a proteção do Direito - e os atos e comportamentos que deveriam ser valorizados ou repudiados no mundo do trabalho - são recuperados através dos processos trabalhistas.

Pertencentes a um universo material e simbólico que contrasta com os da juventude das classes médias, ícones da cultura que os rotulou de rebeldes sem

69 NEGRO, Antonio Luigi. O que a Justiça do Trabalho não queimou: novas fontes para o estudo do trabalho no século XX. Politeia: História e Sociedade, Vitória da Conquista, v.6, n 1, p. 193-209, 2006.

70 BRASIL. Lei $n^{\circ} 7.627$, de 10 de novembro de 1987. Dispõe sobre a eliminação de autos findos nos órgãos da Justiça do Trabalho, e dá outras providências. Disponível em < http://legis.senado.gov.br/legislacao/ListaPublicacoes.action?id=131519>. Acessado em 30 de abril de 2014. Determina a eliminação, por incineração, destruição mecânica ou por outro meio adequado, de autos findos há mais de cinco anos, contado o prazo da data do arquivamento do processo. 
causa, ${ }^{71}$ os jovens da classe trabalhadora também souberam ecoar suas demandas quando seus direitos foram transgredidos ou quando vislumbraram alguma vantagem indenizatória após a rescisão contratual. As fontes da Justiça do Trabalho, ainda que traduzidas pelos signos da linguagem forense, são testemunhas de suas vozes, reclamações e lutas por direitos. Imanente à tímida reflexão aqui fomentada, resvala o convite para a visualização das histórias, reivindicações e, mais do que nunca, para a memória dos rebeldes com causa.

Recebido em: 18/02/2014 Aprovado em: 05/04/2014

71 Cf. PASSERINI, Luisa. La juventud, metáfora del cambio social (dos debates sobre los jóvenes en la Italia fascista y en los Estados Unidos durante los años cincuenta). In: LEVI, Giovanni; SCHMITT, Jean-Claude (orgs.). Historia de los jóvenes II, p. 381-453. 